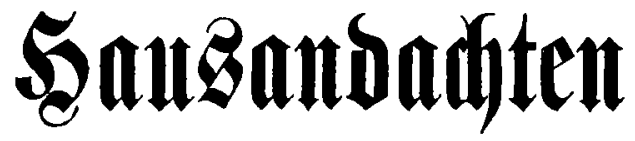

$\mathfrak{a}\lfloor\mathfrak{F}$

\section{Sduletermader's Syredigten,}

in

\section{täglid)en Betrathtungen}

$\operatorname{mat}$

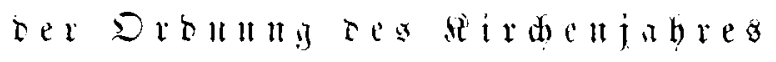

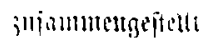

$\mathfrak{1} \mathfrak{1 1}$

T)

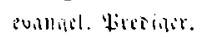

$$
\text { Bweiter Theil. }
$$

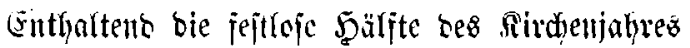

ober bie

Irinitatizeit.

$\mathfrak{B} \mathfrak{c} \mathfrak{\mathfrak { l } i \mathfrak { i t } .}$

Drud uns Berlag vort Beorg Meinter.

1862. 
